\title{
Inventário como ferramenta de preservação: a experiência da cidade de
}

\section{Campinas/SP}

Rita de Cássia Francisco *

\section{Resumo}

Este artigo apresenta a experiência da cidade de Campinas, São Paulo, na realização de um inventário dos bens culturais do município. Primeiramente são apontados aspectos referentes ao início das práticas preservacionistas na cidade, resgatando algumas iniciativas que culminaram, em 1987, na criação do Conselho de Defesa do Patrimônio Cultural de Campinas (Condepacc). Demonstra-se como a atuação do órgão de preservação centrou-se, inicialmente, em respostas a demandas específicas - comumente a salvaguarda de edifícios ameaçados de demolição - sem a realização, por quase vinte anos, de um inventário que the subsidiasse as ações. Por fim, são expostos dados sobre a implantação e o desenvolvimento do "Inventário da Região Central de Campinas", destacando-se a metodologia empregada e os primeiros resultados na orientação das políticas públicas municipais no campo do patrimônio cultural.

Palavras-chave: Patrimônio cultural. Preservação. Inventário.

Inventory as a preservation instrument: the Campinas city's experience (São Paulo State, Brazil)

\section{Abstract}

This paper presents the experience of Campinas City, São Paulo State (Brazil), in the accomplishment of an inventory of cultural resources. Initially are pointed out aspects concerning the beginning of local conservationist practices, rescuing some initiatives that culminated in 1987, the creation of the Conselho de Defesa do Patrimônio Cultural de Campinas [Council for Protection of Campinas Cultural Heritage] (Condepacc). It shows how the preservation institution's performance was initially focused on answers to specific demands - commonly the safeguarding of buildings threatened with demolition - without the holding, for almost twenty years, an inventory that subsidized its activities. Finally, are exposed informations on the 
deployment and development of the inventory of the Campinas Central Region, such a methodology employed and the first results in guiding public policy in the municipal cultural heritage subject.

Key-words: Cultural heritage. Preservation. Inventory.

\section{Inventário como ferramenta de preservação: a experiência da cidade de}

\section{Campinas/SP}

\section{Notas preliminares}

As primeiras ações relacionadas à preservação dos bens culturais de Campinas, São Paulo, remontam a meados dos anos 1980 e estão, no âmbito municipal, vinculadas à movimentação de representantes da sociedade civil organizados em um grupo que ficaria conhecido como Sociedade Febre Amarela. Oficializada em 15 de março de 1985, pelos arquitetos Antonio da Costa Santos, Sérgio Portella Santos e Luiz Cláudio Bittencourt, a Febre Amarela viria a marcar o cenário campineiro nos anos seguintes com várias ações em defesa do patrimônio cultural da cidade.

Sobre o intrigante nome da sociedade, vale lembrar que Campinas sofreu, na passagem do século XIX para o XX, o que o historiador José Roberto do Amaral Lapa chamou de "a ronda das epidemias", tendo sido vítima de surtos de tifo amarelo, cólera, varíola e febre amarela. Esta última, dentre todas, foi a mais devastadora das epidemias, dizimando grande parte da população e marcando definitivamente a história local (LAPA, 1996, p. 243-274). Em 1996, no debate público "Campinas: preservar ou destruir" Antonio da Costa Santos, numa breve explanação, diria apenas - e provocativamente - que: "o surto daquela doença que assolou o país chegou a Campinas e forçou a administração municipal a realizar várias obras de saneamento básico, mudando inclusive o traçado urbano". (UM DEBATE, 1986). Como veremos adiante, esse novo surto também acarretaria novas posturas por parte da prefeitura municipal, culminando com a criação do Conselho Municipal de Defesa do Patrimônio. 
Dentre os vários atos do grupo, mencionaremos aqui dois deles, os quais acreditamos fundamentais para a compreensão do início das práticas preservacionistas em Campinas, objetivo principal dessas notas. A primeira situação polêmica envolvendo a Febre Amarela ocorreu em 1986, apenas um ano depois de sua oficialização, quando a Prefeitura Municipal determinou alterações no tradicional Largo do Rosário. Situada na área envoltória da Catedral Metropolitana, tombada pelo Conselho de Defesa do Patrimônio Histórico, Arqueológico, Artístico e Turístico do Estado de São Paulo (Condephaat), a praça não poderia ter sofrido alterações sem prévia autorização do órgão. As discussões acirradas em torno da questão trariam à tona, pela primeira vez, a necessidade de criação de um órgão municipal que pudesse gerir de perto as questões relativas à preservação do patrimônio do município (CARDILLO, 1988).

O debate acirrar-se-ia ainda mais no ano seguinte, com as ações de combate à demolição do prédio da antiga fundição Lidgerwood Manufacturing Co. (1) Em julho de 1987 Santos, então presidente da sociedade, recebeu a denúncia de que o edifício, daquela que foi uma das primeiras fábricas de Campinas, seria demolido para implantação de alterações no sistema viário do Centro da cidade. $O$ arquiteto filmou os técnicos no local, registrou boletim de ocorrência e, a partir de então, membros da Febre Amarela e moradores da região montaram vigília no local, culminando com o simbólico abraço da edificação. $O$ fato também foi levado ao conhecimento do Condephaat, que, com as informações prestadas acerca da relevância do imóvel, deu início ao seu estudo de tombamento (PORTINARI, 1987a).

O apelo ao Condephaat, órgão estadual, deu-se em função da inexistência de um órgão na instância municipal. Em 1979 o então prefeito Francisco Amaral havia desenvolvido, juntamente com entidades civis preservacionistas de Campinas, um projeto para a formação do conselho local de defesa do patrimônio histórico. O projeto, praticamente esquecido, foi alterado já em 1985 pelo prefeito Magalhães Texeira, que inseriu a participação de secretarias municipais na composição do Conselho (PORTINARI, 1987a). Após o encaminhamento à Câmara Municipal para análise, o projeto permaneceu engavetado até 1987, quando um novo surto da Febre Amarela provocaria novamente a reação da administração. 
O prefeito Magalhães Teixeira declarou, à época, não considerar a determinação de se preservar o prédio da fundição Lidgerwood como uma derrota para seus opositores da Febre Amarela (PRESERVAÇÃO, 1987). Mas o fato é que, além dos necessários ajustes na reformulação viária, Campinas já teria, enfim, ainda em dezembro de 1987, seu conselho local de defesa do patrimônio. (2)

O Conselho de Defesa do Patrimônio Cultural de Campinas (Condepacc) foi criado pela Lei Municipal №. 5885 de 17 de dezembro de 1987, (3) com a função de definir a política municipal de defesa e proteção do patrimônio histórico, artístico, estético, arquitetônico, arqueológico, documental e ambiental do município de Campinas e ainda coordenar, integrar e executar as atividades públicas referentes a essa política (FRANCISCO, 2005, p. 20).

Apesar disso, as primeiras realizações do Condepacc, assim como aquelas levadas a cabo pelos membros da Sociedade Febre Amarela, configuraram-se mais como respostas a demandas específicas - mormente a salvaguarda de edifícios ameaçados de demolição - que propriamente como fruto do estabelecimento de uma política pública para o campo do patrimônio cultural da cidade. Embora junto da criação do Conselho tenha acontecido também a criação da Coordenadoria do Patrimônio Cultural (CPC) - atualmente Coordenadoria Setorial do Patrimônio Cultural (CSPC) -, órgão que the subsidiaria as ações, (4) pode-se dizer que os critérios para os tombamentos eram sustentados mais pela autoridade dos agentes envolvidos que propriamente por estudos e pesquisas. (5)

As primeiras iniciativas do Condepacc refletiram, desse modo, a prioridade de se assegurar a proteção legal de alguns bens já notadamente reconhecidos como patrimônio da cidade - alguns inclusive preservados nas instâncias estadual e/ou federal - por meio da inscrição no Livro Tombo. Destarte, os primeiros tombamentos do órgão contemplaram apenas bens isolados, (6) quase exclusivamente solares dos barões de café ou templos religiosos. (7)

Das informações apresentadas pode-se depreender que não houve, de início, nenhum intento de se realizar um inventário, entendido como instrumento auxiliar ao planejamento da conservação dos bens culturais do município. Quanto aos anos 
seguintes, há nos arquivos da CSPC inúmeros documentos, elaborados ao longo das duas últimas décadas, associados à tentativa de realização de um inventário, com séries de fichas de imóveis, registros gráficos e fotográficos.

Dizemos tentativa pois não encontramos, no entanto, indícios de que esse material tenha sido articulado para auxiliar na determinação das políticas de preservação em Campinas, alinhando-se a um modelo de inventário profundamente vinculado à idéia de catalogação e registro, ou seja, ao processo de identificação, documentação e classificação, apenas.

Ocorre, no entanto, que as informações e registros não possuem valores em si mesmos. Somente contribuem para a produção de conhecimento no campo da preservação à medida que se articulam a determinadas questões previamente colocadas pelos técnicos envolvidos no processo. Adicione-se a isto o fato de que, mais recentemente, com a crescente complexidade das tarefas de gestão do patrimônio cultural e a necessidade de acompanhamento e avaliação de procedimentos, técnicas, planos e projetos desenvolvidos, o inventário passou a ser reconhecido como um dos mais importantes instrumentos de planejamento e gerenciamento da conservação. Nas palavras de Vera Milet, esse reconhecimento:

[...] levou a que o inventário, na atualidade, seja entendido como um instrumento vivo, em constante atualização, capaz de instrumentalizar o processo de planejamento da conservação, à medida que permite o gerenciamento das informações relativas a valores, estado de conservação, estado de preservação, vulnerabilidade (riscos) e capacidade de carga do sítio. Todos esses elementos são de suma importância para o controle da mudança, para a avaliação e o monitoramento do plano de conservação, assim como para o estabelecimento das prioridades de intervenção. (MILET, 2002, p. 130).

Com base nessas questões, a CSPC vem desenvolvendo pela primeira vez em Campinas, apesar dos vinte anos da criação do Condepacc, um inventário de bens culturais. Isso porque, considerando-se as recentes discussões sobre a dimensão e o alcance desse instrumento, é a primeira vez que as atividades de catalogação e registro não se constituem como um fim em si, mas sim como meio para a implantação e o desenvolvimento de uma ferramenta a serviço da preservação. 


\section{0 desenvolvimento de um inventário para Campinas: projeto e recortes}

A viabilização de um inventário para os bens culturais de Campinas teve início com o aceite do projeto "Inventário como ferramenta para a preservação do patrimônio cultural" pelo Programa de Políticas Públicas da Fundação de Amparo à Pesquisa do Estado de São Paulo (Fapesp) no ano de 2004. Iniciativa da Professora Dra. Silvana Rubino e da coordenadora da CSPC, Daisy Serra Ribeiro, a proposta criou as condições formais para a parceria entre a Universidade Estadual de Campinas (Unicamp) e o órgão local do patrimônio.

A proposta inicial, visando auxiliar a implantação de políticas públicas eficazes e democráticas no município de Campinas, foi iniciar um extenso inventário, incluindo um estudo aprofundado sobre a legislação vigente no país, e mais especificamente em Campinas, e sobre as regras e procedimentos adotados internacionalmente. Considerava Silvana Rubino à época:

\footnotetext{
Dizemos iniciar, pois a pesquisa reconhece a necessidade de abrangermos todos os campos do abrangente conceito de patrimônio cultural. No entanto, inventários específicos requerem metodologias particulares, e, por circunscrição temática e temporal, vamos nos ater ao inventário dos bens imóveis de uma região da cidade. (RUBINO, 2004).
}

Assim, a Secretaria Municipal de Cultura de Campinas, por meio da CSPC, vem, desde meados de 2005, desenvolvendo estudos para realização de um inventário dos bens culturais situados na região central do município, (8) guiando-se pelas diretrizes adotadas no "Inventário Nacional de Bens Imóveis dos Sítios Urbanos Tombados (INBI-SU)", desenvolvidas pelo Instituto do Patrimônio Histórico e Artístico Nacional (Iphan) desde 1998 (MINC/IPHAN, 2001). (9) De forma geral, pode-se dizer que as pesquisas subsidiárias ao inventário desenvolvidas pela CSPC vêm buscando:

- Contribuir para o estabelecimento de critérios e parâmetros delineadores das políticas públicas de preservação do patrimônio; (10)

- Apoiar os trabalhos de planejamento urbano; 
- Constituir-se em uma ação de preservação, na medida em que se conservam em outros suportes as informações contidas nos bens originais;

- Constituir-se como ferramenta também das atividades posteriores ao tombamento, como restauros ou outras intervenções;

- Atualizar informações sobre as intervenções nos bens ao longo dos anos.

Estabelecidas as orientações basilares pela coordenadora geral do projeto, Profa. Silvana Rubino, coube à equipe de trabalho iniciar as pesquisas preliminares para estabelecimento dos recortes a serem trabalhados e da metodologia a ser empregada para consecução dos objetivos inicialmente traçados. (11)

Atendo-nos, conforme mencionado anteriormente, ao inventário dos bens imóveis de uma determinada região da cidade, optamos por abordar o que a equipe denominou de "Região Central de Campinas", conglomerando o Centro propriamente dito e trechos de outros bairros que Ihe são adjacentes. O perímetro adotado para estudo (Figura 1) baseou-se na primeira planta cadastral de Campinas, levantada em 1929, na gestão do então prefeito Orosimbo Maia, (12) e contempla significativa parte dos bens tombados ou em estudo de tombamento pelo Condepacc, incluindo a poligonal estabelecida como Centro Histórico pelo Decreto no. 10.424 de 06 de maio de 1991.

O recorte espacial adotado nos auxiliou a estabelecer, por conseqüência, os limites do recorte temporal - ao menos para o início da longa pesquisa documental. Abrange o período entre os anos de 1872, marco da chegada da ferrovia à cidade, (13) e 1929, data da já citada planta cadastral, abordagem que se justifica pela possibilidade de apreender a transformação da Campinas que começou a tomar forma urbana nesse período - inferência facilmente verificada ao contrapormos, por exemplo, mapas do município de 1878 e 1929.

A delimitação espacio-temporal não pretendeu justificar a preservação do patrimônio com base em critérios de antiguidade ou de vinculação com determinados momentos históricos. Tampouco se tratou de delimitar com esse recorte a 
documentação catalogada e a se analisar. (14) De modo geral, os recortes adotados configuraram-se mais como um recurso metodológico para que, no escopo desse projeto, pudéssemos iniciá-lo e torná-lo factível.

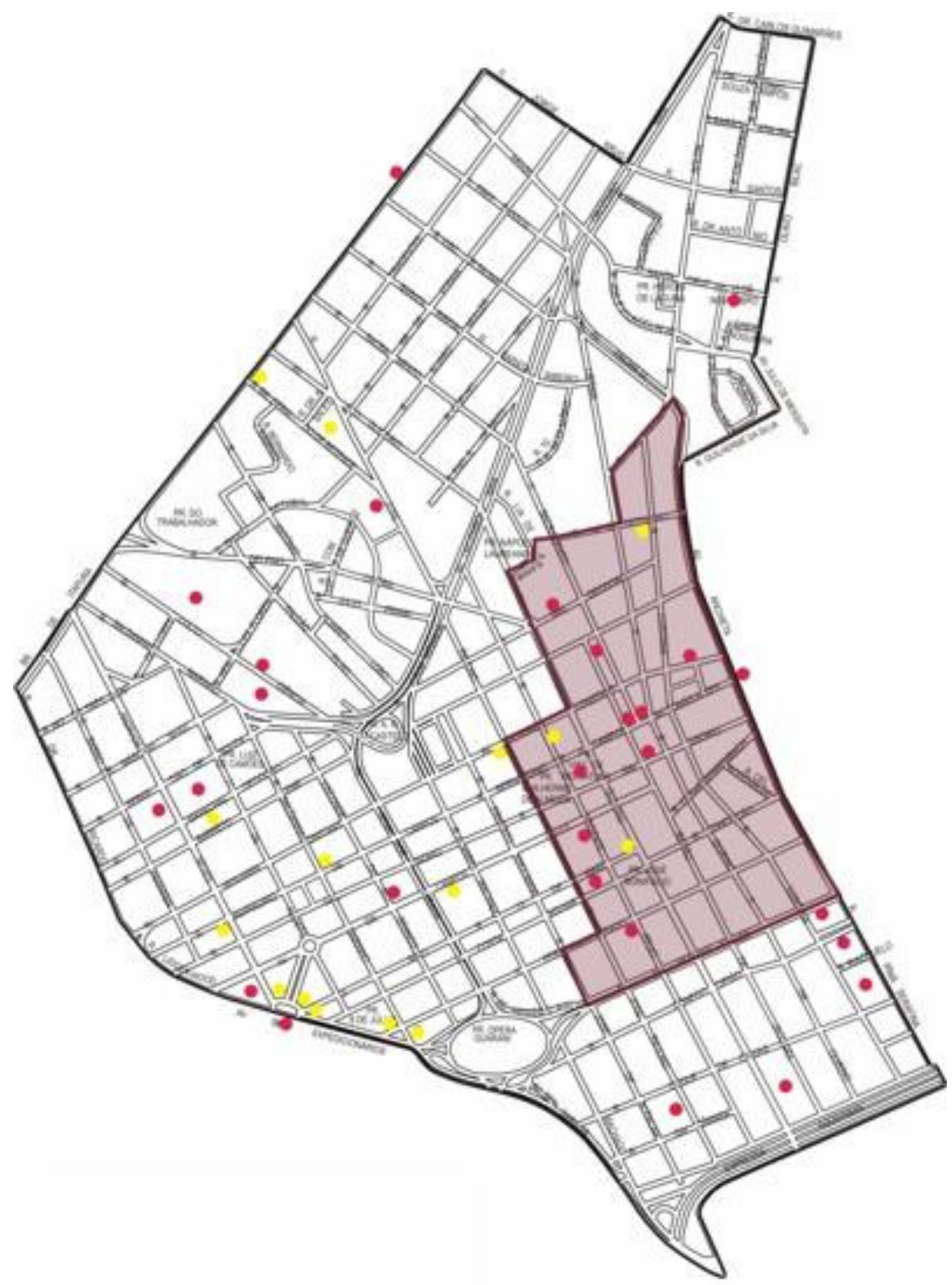

FIGURA 1 - Mapa com a delimitação da área de estudo do "Inventário da Região Central de Campinas". Partindo da extremidade inferior do mapa, temos, no sentido anti-horário: Avenida Aquidaban, Rua Irmã Serafina, Avenida Anchieta, Rua Guilherme da Silva, Avenida Julio de Mesquita, Rua Olavo Bilac, Rua Carlos Guimarães, Avenida Orosimbo Maia, Rua Jorge Krug, Avenida Barão de Itapura, Rua Dr. Ricardo, Rua Lidgerwood e Avenida dos Expedicionários. No destaque, vê-se a área do Centro Histórico. Os pontos vermelhos representam a localização aproximada dos bens tombados pelo Condepacc e os pontos amarelos, dos bens em estudo de tombamento. Desenho da autora. 


\section{Metodologia e atividades desenvolvidas}

Estabelecidos os limites para o desenvolvimento do "Inventário da Região Central de Campinas", as tarefas formuladas concentraram-se em atividades de duas naturezas principais: a pesquisa documental e a pesquisa de campo.

A pesquisa documental contemplou a coleta de informações gerais sobre o processo de ocupação e crescimento do sítio a ser inventariado por meio do levantamento de fontes bibliográficas - livros, folhetos, periódicos, etc. - e do levantamento de fontes arquivísticas. Dentre essas últimas destacaram-se relatórios, atas da Câmara, posturas municipais, requerimentos e protocolos relativos à aprovação de projetos de edificação - classificados como documentação textual - além de plantas, fotografias e outros materiais iconográficos - classificados como documentação especial.

As pesquisas de campo, por sua vez, tiveram por objetivo a realização de um levantamento físico-arquitetônico do conjunto edificado na área delimitada para estudo, visando obter registros gráficos e fotográficos, além de dados sobre o lote, o tipo de implantação e a configuração arquitetônica das edificações. Em meio aos principais recursos utilizados para tanto, podemos citar o levantamento métricoarquitetônico - com a elaboração de croquis de plantas, fachadas e composição de volumes - e o registro em ficha de pré-inventário das condições físicas de cada imóvel - contemplando identificação do tipo e estado de conservação de sistemas estruturais, coberturas, materiais de revestimento, ornamentos, vãos, caixilharia, etc.

Dentre as atividades relacionadas à pesquisa de fontes primárias, a primeira e principal atividade da equipe foi debruçar-se sobre uma base material ainda não catalogada, pertencente ao acervo do Arquivo Municipal de Campinas. Durante o período de outubro de 2005 a dezembro de 2006, uma equipe de seis estagiários procedeu à catalogação em ficha impressa de um conjunto de pedidos protocolados na Prefeitura entre 1892 e 1929, abrangendo desde cercamento e delimitação de lotes até aprovação de projetos de edificações, passando por pequenos reparos, 
reformas, construção de anexos, adaptação de prédios a novas funções, reconstruções, demolições, etc.

Esse trabalho deu origem a um conjunto de 6935 fichas que, depois de previamente organizadas - obedecendo ao critério de requerimentos por rua, número do imóvel e ano, respectivamente - foram digitadas e catalogadas provisoriamente em base de dados da plataforma do Microsoft Access. A tabulação dos dados obtidos, ainda que incipiente até o presente momento, já se configura como um contributo à apreensão do processo de formação da mancha urbana de Campinas, trazendo novos esclarecimentos sobre as mudanças espaciais - ao possibilitar a leitura dos eixos de desenvolvimento de Campinas ao longo dos anos abordados pela pesquisa - e sobre os atores sociais responsáveis pelas mesmas - proprietários, engenheiros-arquitetos e construtores.

Atualmente, para incrementar a sistemática de organização dos dados, encontra-se em andamento o projeto de criação de um sistema específico para tal fim pela Informática de Municípios Associados S/A (IMA), autarquia do município especializada em tecnologia da informação e comunicação. Tal iniciativa leva em consideração o fato de que

[...] a ciência da informação tem sido uma grande aliada do planejamento da conservação do patrimônio cultural, na medida que possibilita o acesso à armazenagem e o tratamento de grande quantidade de dados e, simultaneamente, possibilita a democratização das informações. Além disso, a informatização assegura que a coleta, o processamento e a transmissão dos dados tenham seus custos reduzidos. Isso se dá tanto pela capacidade de armazenamento e relacionamento, como também pela possibilidade de criação de redes. Nesse sentido, é importante pensar maneiras de organizar as informações de modo a permitir uma otimização dos dados (cooperação) e dos recursos investidos. (MILET, 2002, p. 128).

Concomitantemente a essas atividades descritas para a pesquisa no Arquivo Municipal, deu-se início aos trabalhos de campo do inventário. Um modelo de ficha de pré-inventário foi desenvolvido pela equipe para o registro das condições físicas de cada imóvel, no que tange à sua caracterização geral, tipologia, elementos construtivos e estado de conservação. Essas informações, assim como registros 
gráficos e fotográficos dos imóveis foram igualmente armazenados provisoriamente em banco de dados em plataforma Microsoft Access. (15)

Durante os trabalhos de campo, que ocorreram sistematicamente durante os anos de 2006 e 2007, foram visitados e inventariados cerca de 760 imóveis, dentre os quais aproximadamente 300 foram selecionados para estudos detalhados que podem vir a compor a instrução de futuros processos de tombamento. Espera-se que os dados catalogados configurem-se como importante instrumento para avaliação do estado de alteração dos imóveis inventariados, e também para a quantificação e a qualificação do montante das edificações outrora perdidas - ao relacionarmos essa base àquela gerada a partir das pesquisas documentais devido à ausência das políticas públicas voltadas à preservação do patrimônio cultural, aos processos de urbanização e/ou às escolhas urbanísticas.

Por fim, na fase final do projeto, ainda em desenvolvimento, espera-se relacionar todos os dados obtidos e organizar um dossiê completo de cada um dos imóveis selecionados para estudo dentro da área inicialmente adotada. Para tanto, será elaborada uma nova ficha que aglutinará todas as informações a respeito da edificação, desde aquelas obtidas nas plantas e solicitações à Prefeitura, até aquelas referentes ao seu estado atual e às características arquitetônicas, além de materiais gráficos diversos representativos do imóvel em diferentes períodos planta de situação, fotografias, croquis, etc.

O intuito é a realização de um inventário de bens imóveis, analisados em suas dimensões urbanística, histórica, sócio-cultural e arquitetônica que possa, conforme apontado desde o início das discussões, subsidiar a política de preservação e, por conseguinte, as intervenções na área central - e em outras áreas, por desdobramentos - da cidade de Campinas.

Todo o resultado da pesquisa deverá estar disponível para consulta no Centro de Documentação da CSPC e ser publicado no portal da Prefeitura Municipal de Campinas, especificamente no sítio do patrimônio cultural, (16) onde o banco de dados produzido estará acessível à população, tornando as políticas de preservação 
mais transparentes e compreensíveis, e a pesquisadores, como subsídios para suas investigações. (17)

\section{Resultados preliminares}

Após os primeiros contatos com as fontes documentais e materiais, a equipe se dedicou a analisar os dados coletados para sistematizá-los, de modo a garantir sua legibilidade, e organizá-los em séries documentais que pudessem vir a contribuir para a instrumentalização dos técnicos do patrimônio cultural na revisão dos critérios e normas de proteção das áreas tombadas do sítio urbano.

Como novo recurso metodológico, a equipe optou pela divisão dos limites inicialmente adotados como recorte de estudo em cinco subáreas, delimitadas em função de padrões urbanísticos de ocupação, características de implantação e tipologia predominante das edificações. Além disso, teve-se em conta ainda a preexistência de áreas envoltórias de bens tombados, cuja regulamentação contribuiu para a disciplinarização - e conseqüente configuração — das atuais formas de ocupação, visando à ambiência e à contextualização de tais bens. Com esse olhar, foram estabelecidos os seguintes novos recortes (Figura 2):

\section{Área 1}

Delimitada por: Avenida Senador Saraiva, Avenida Orosimbo Maia, Avenida Anchieta, Rua Irmã Serafina e Avenida Moraes Salles. Trata-se de extrapolação da área definida como Centro Histórico. Concentra os seguintes bens tombados: Solar do Visconde de Indaiatuba; Solar do Barão de Itapura; Palácio dos Azulejos; Catedral Metropolitana; Solar do Barão de Ataliba Nogueira; Jóquei Clube Campineiro; Mercado Municipal; Antigo Colégio Coração de Jesus; Praça Visconde de Indaituba; Praças Bento Quirino e Antonio Pompeu; Basílica Nossa Senhora do Carmo; Casa da Banda Carlos Gomes; Imóvel na Rua Dr. Quirino 1396 e 1404. E os seguintes bens em estudo de tombamento: Antigo Hotel Terminus; Imóvel na Avenida Campos Salles, 514; Imóvel na Rua José Paulino, 1271; Imóvel na Rua Regente Feijó, 1288; Imóvel na Rua Lusitana, 1667. 


\section{Área 2}

Delimitada por: Avenida dos Expedicionários, Rua Lidgerwood, Rua Dr. Ricardo, Rua Barão de Itapura, Rua Saldanha Marinho, Avenida Senador Saraiva e Rua Jayme Pinheiro Ulchoa Cintra. Trata-se de extrapolação da área envoltória do Complexo Ferroviário Central de Campinas, (18) excetuando-se a porção pertencente à Vila Industrial, objeto de estudo específico. Concentra os seguintes bens tombados: Lidgerwood Manufacturing Ltda.; Palácio da Mogiana; Delegacia Regional de Polícia de Campinas; Hospital Beneficência Portuguesa. E os seguintes bens em estudo de tombamento: Galpão Industrial da Avenida Andrade Neves; Traçado Urbanístico da Praça 9 de julho; Prédios geminados na Rua Saldanha Marinho, 66, 70 e 115; Praça Marechal Floriano Peixoto; Monumento da Companhia Mogiana; Prédios assobradados da Avenida dos Expedicionários, 288; Edifício Roque de Marco; Antigo Hotel Grigoletti; Praça Luís de Camões; Imóvel na Avenida Andrade Neves, 471; Palacete do Hospital Vera Cruz; Imóvel na Rua Bernardino de Campos, 407; Imóvel na Rua Ferreira Penteado, 17/23/29.

\section{Área 3}

Delimitada por: Avenida Senador Saraiva, Avenida Moraes Salles e Avenida Aquidabã. Trata-se de extrapolação da área envoltória da Praça Sílvia Simões Magro. Concentra os seguintes bens tombados, além da citada praça: Creche Bento Quirino; Casa de Saúde; Igreja São Benedito; Externato São João; Largo do Pará.

\section{Área 4}

Delimitada por: Rua Saldanha Marinho, Avenida Barão de Itapura, Rua Jorge Krug e Avenida Orosimbo Maia. Trata-se de extrapolação da área envoltória dos Colégios Culto à Ciência e Bento Quirino (atual Colégio Técnico da Unicamp - Cotuca), no bairro Botafogo, além de parte da Vila Itapura. Concentra, além dos colégios já citados, os seguintes bens tombados: Antiga Fábrica de Tecidos Elásticos Godoy e Valbert S/A; Instituto Agronômico de Campinas; Imóvel na Rua Culto à Ciência, 238. E os seguintes bens em estudo de tombamento: Fábrica de Chapéus Vicente Cury; Imóvel na Avenida Barão de Itapura, 860.

\section{Área 5}

Delimitada por: Avenida Anchieta, Avenida Orosimbo Maia, Rua Dr. Carlos 
Guimarães, Rua Olavo Bilac, Avenida Júlio de Mesquita e Rua Guilherme da Silva. Trata-se da área de ocupação mais antiga do bairro Cambuí. Concentra o seguinte bem tombado: Capela de Santa Cruz.

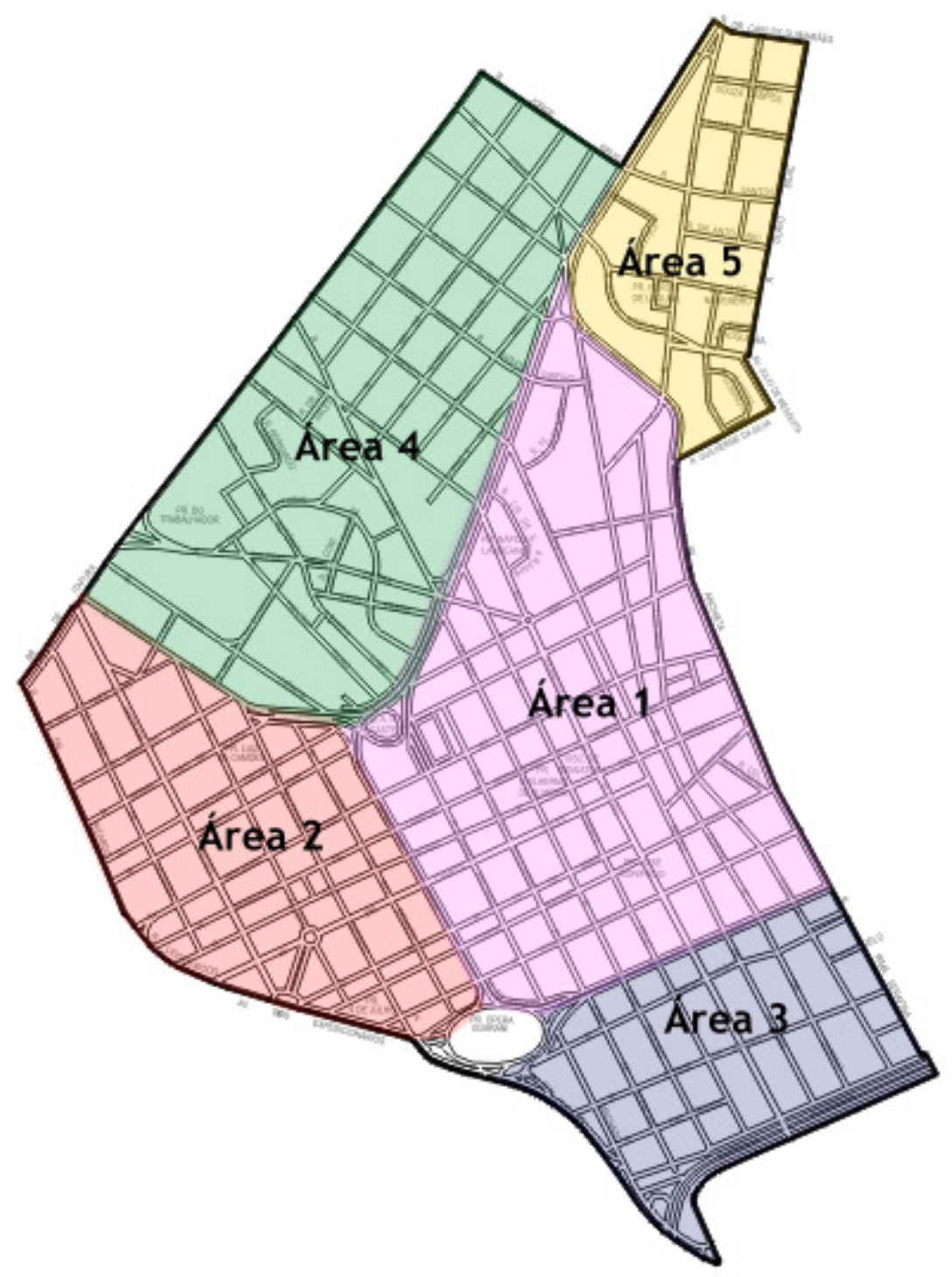

FIGURA 2 - Subáreas de estudo do "Inventário da Região Central de Campinas". Desenho da autora.

Após esses esboços iniciais, e estabelecendo como base do trabalho a noção de cidade-documento, entendida como "[...] o lugar socialmente produzido, onde se acumulam vestígios culturais sucessivos resultantes da permanente apropriação das coisas do passado, documentando a trajetória de uma sociedade" (MINC/IPHAN, 2001), a equipe passou a se dedicar ao detalhamento do estudo da Área 2. Tal opção fez-se em função do grande número de imóveis listados como preservados na 
Resolução $n^{\circ}$. 04/90 do Condepacc, que dispõe sobre o tombamento do Complexo Ferroviário Central de Campinas, e da decorrente fragilidade desta figura.

Ao menos durante a primeira década de atuação do Condepacc, foi comum o emprego do termo preservado nas resoluções de tombamento, utilizado para designar bens situados na área envoltória dos bens tombados que não poderiam ser modificados ou demolidos sem prévia autorização do conselho, em diferentes graus (preservação total, preservação de fachada e/ou volumetria, por exemplo). $\mathrm{Na}$ prática, esses imóveis ficavam, em muitas vezes, submetidos às restrições impostas a um imóvel tombado, sem que o fossem juridicamente. Por outro lado, não caberiam aos proprietários os benefícios concedidos àquela figura, como a concessão de isenção de imposto predial territorial urbano (IPTU), ou a possibilidade de concorrer a linhas de financiamentos para recuperação dos imóveis.

Além disso, durante os trabalhos de campo do inventário, foi possível verificar que muitos dos imóveis preservados em resoluções se encontram desfigurados. Por esse motivo propusemos uma completa revisão dessa situação, culminando com o tombamento daquelas edificações significativas e ainda íntegras - individualmente ou em conjuntos urbanos - e a retirada da listagem daquelas descaracterizadas ou mesmo demolidas parcialmente das respectivas resoluções em que estiverem arroladas nos termos ora descritos.

Para tanto, o material coletado na pesquisa histórica e na pesquisa de campo, a subseqüente sistematização dos dados, o mapeamento do processo de ocupação e ordenamento territorial, a análise tipomorfológica e, enfim, a identificação do estado de preservação dos imóveis foram organizados de modo a constituir-se no corpo do primeiro estudo de tombamento originado pelo "Inventário da Região Central de Campinas".

Mesmo com a apresentação dos resultados em reunião ordinária do Condepacc de 13 de setembro de 2007, o estudo ainda não foi aberto e aguarda a tramitação em diversas instâncias da Prefeitura Municipal de Campinas. A partir do Decreto $n^{\circ}$. 15.471 de 16 de maio de 2006, após análise preliminar do conselho, os pedidos de abertura de estudos de tombamento considerados pertinentes devem ser 
encaminhados às Secretarias Municipais de Urbanismo, de Planejamento, Desenvolvimento Urbano e Meio Ambiente e de Assuntos Jurídicos, para "elaboração de pareceres técnicos". Somente depois do aval desses três órgãos é que o Condepacc poderá emitir sua — dita — soberana decisão.

Apesar do enfrentamento com a primeira grande dificuldade de implementação das políticas propostas a partir do inventário, a equipe deu continuidade aos trabalhos. Os procedimentos adotados para a Área 2 foram aplicados nas outras quatro subáreas restantes (ver Figuras 3 a 8), de modo que em janeiro de 2008 foram concluídos os estudos preliminares para a íntegra de nossa área de estudo.

A finalização dos recortes parciais possibilitou que retornássemos novamente ao perímetro que denominamos "Região Central de Campinas" e, com isso, novas possibilidades de agrupamento dos conjuntos se descortinaram.
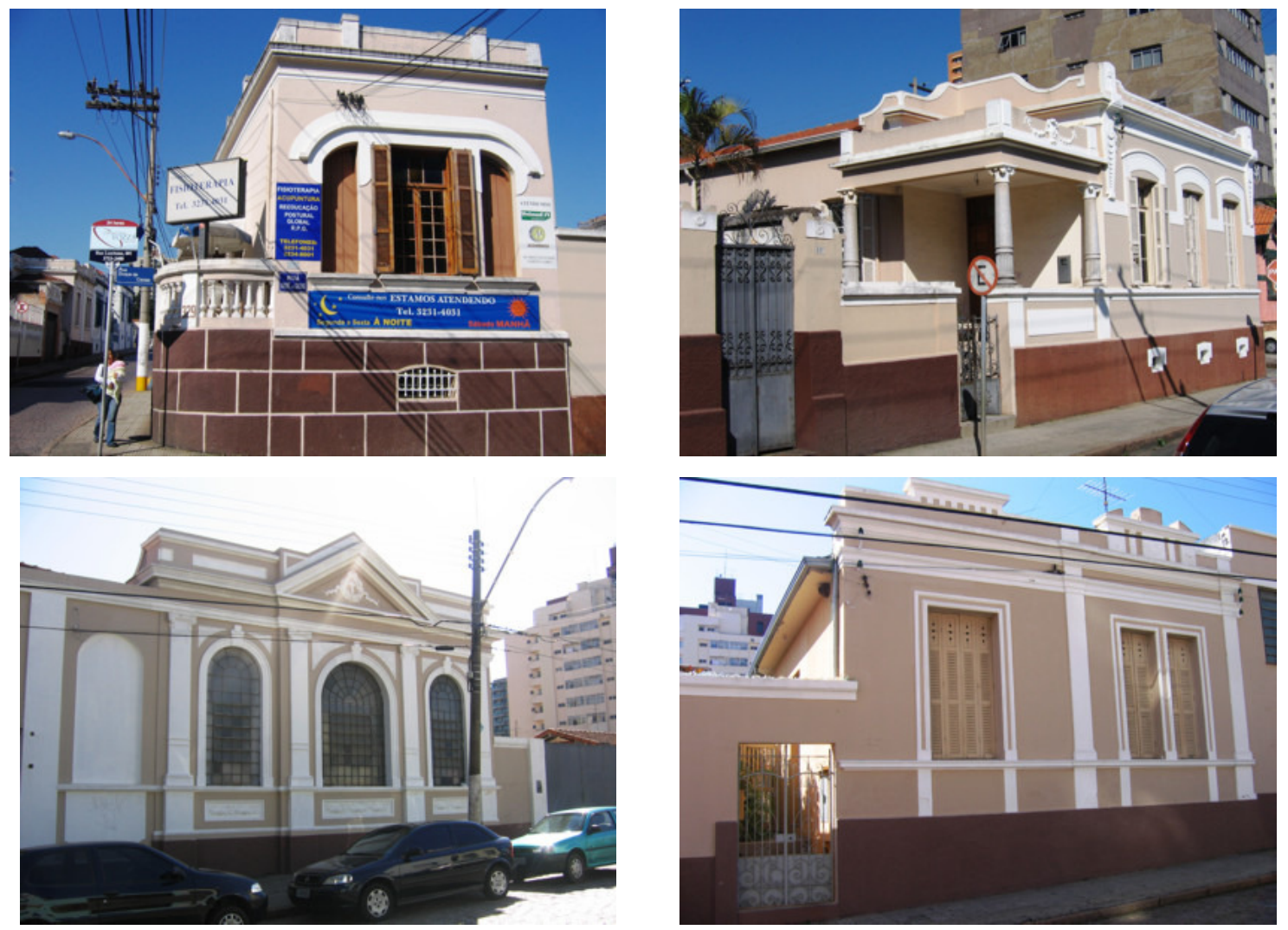

FIGURAS 3 a 6 - Exemplo de um dos conjuntos urbanos existentes na Área 3 do inventário. Trata-se de imóveis pertencentes ao Hospital Casa de Saúde, cujo tombamento pelo Condepacc contemplou apenas o edifício principal, de modo que o entorno apresentado nas imagens permanece sem proteção legal. Fotos da autora. 

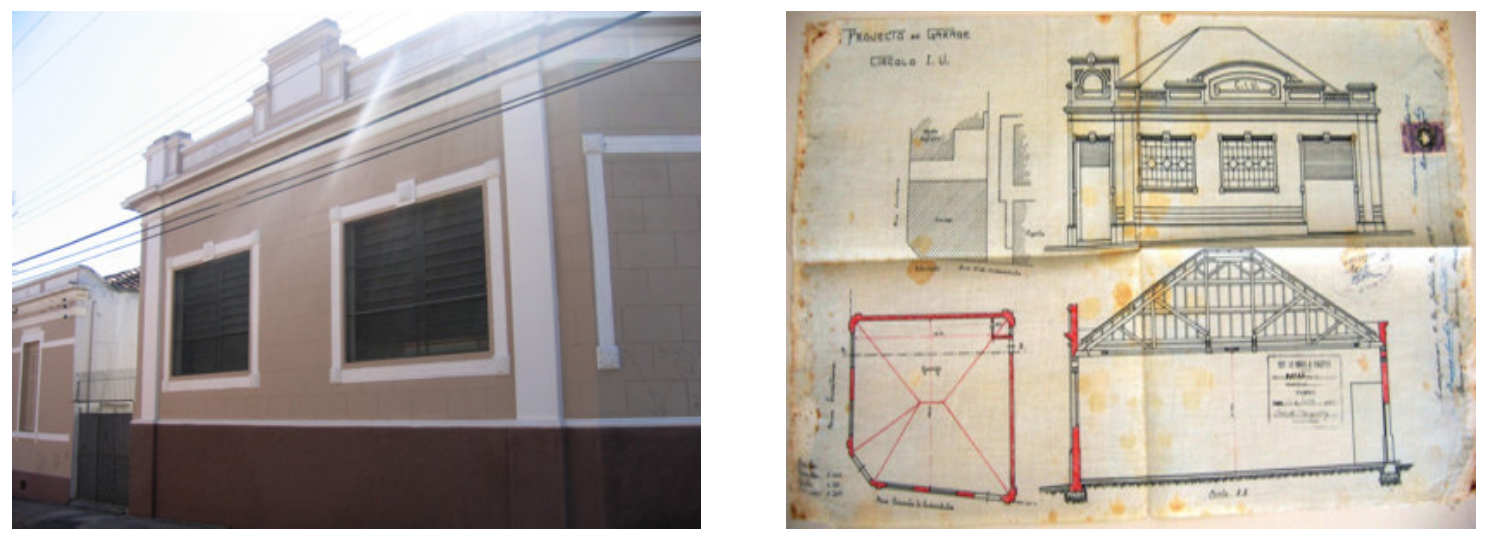

FIGURAS 7 e 8 - Imóvel pertencente ao conjunto da Casa de Saúde, originalmente construído como garagem do então Hospital Circolo Utaliani Uniti, conforme projeto de construção apensado a requerimento datado de 09 de julho de 1929. Fotos da autora. Reprodução do acervo do Arquivo Municipal de Campinas.

Para citar um exemplo, podemos falar dos conjuntos urbanos da Rua 13 de maio, presentes nas subáreas 1 e 2. Em vez de considerá-los individualmente, a opção da equipe foi estabelecer o "Conjunto urbano da Rua 13 de maio", passível de um tombamento que considerasse, além das edificações propriamente ditas, a configuração da tradicional via de pedestres consolidada desde sua formação como corredor comercial, incluindo estudos sobre os gabaritos de altura e publicidades a serem admitidos.

Todas essas possibilidades de encaminhamento dos estudos aguardam, no entanto, aval das instâncias superiores para prosseguimento. Apesar da insistência da equipe, nunca foi emitido sequer um comunicado no Diário Oficial do Município sobre a realização do inventário, de tal maneira que o mesmo permanece sem um caráter oficial. Como apenas uma das várias conseqüências dessa situação, podemos citar a inoperância diante dos inúmeros pedidos de demolições de imóveis inventariados mas sem nenhuma proteção legal pela legislação do Condepacc. Afinal, se o inventário não existe oficialmente, como utilizá-lo como justificativa para negar tais solicitações?

\section{Considerações finais}

Decorridos dois anos de desenvolvimento do projeto do "Inventário da Região Central de Campinas", já é possível verificar a repercussão das atividades efetivadas 
e realizar um balanço, tanto dos avanços trazidos quanto das deficiências e dificuldades a superar.

Iniciando pelas tarefas internas à CSPC, o material gerado pelo inventário passou a subsidiar a equipe técnica na apreciação dos requerimentos relativos à intervenção em bens tombados ou ainda a reformas, demolições e novas construções nos citados imóveis preservados, situados em áreas envoltórias. O acesso facilitado aos arquivos com informações sobre projetos, alterações nos imóveis ao longo dos anos e atual estado de conservação vem permitindo, além do monitoramento do sítio, maior embasamento para avaliação da pertinência ou não de tais solicitações.

A consistência dos dados coletados também foi fundamental para o estabelecimento de um maior contato com outras secretarias da Prefeitura Municipal de Campinas, que passaram a procurar a CSPC antes do fechamento de projetos urbanísticos que interfiram na região central. Como exemplo, podemos citar as experiências bem sucedidas com a Secretaria Municipal de Planejamento, Desenvolvimento Urbano e Meio Ambiente (Seplama) e com a Secretaria Municipal de Urbanismo (Semurb).

No primeiro caso, a Seplama vem desenvolvendo estudos para o entorno da nova rodoviária de Campinas - em construção em área interna ao Complexo Ferroviário —, os quais prevêem alterações no traçado urbano, mudanças no tráfego e bolsões de estacionamento. Desde o início, os estudos do inventário, especificamente aqueles da Área 2, mais diretamente relacionada ao local das intervenções, foram fornecidos à equipe responsável e, além disso, a CSPC tem sido chamada a participar do grupo que discute a questão. No segundo caso, aventa-se a possibilidade de adoção, por parte da Semurb, da área do inventário para um projeto de regulamentação especial de publicidade no centro histórico.

Apesar dessas situações pontuais, ainda há, dentro da própria Prefeitura Municipal, uma grande incompreensão sobre o que vem a ser o inventário e sobre suas reais finalidades. Para se ter uma idéia, a revista "Ver e Ouvir" - publicação institucional da Secretaria de Cultura - de novembro de 2007, cuja matéria de capa foi o inventário, trazia o seguinte título para seu editorial: "Sinal verde para o 
crescimento". O foco da reportagem foi mostrar que o inventário serviria para definir a situação dos imóveis situados no centro histórico de Campinas, incidindo sobre

[...] o efetivo tombamento ou a liberação para negociação e/ou realização de quaisquer tipos de intervenções, como ampliações e reformas. Isso permitirá, como se depreende, a liberação de extensas áreas localizadas no centro histórico de Campinas para novos empreendimentos residenciais ou empresariais, alavancando o crescimento e o progresso da cidade [...]. (SINAL, 2007, contracapa).

Os jornais locais, por sua vez, também contribuíram para o crescimento do mito em torno do inventário. Na data de uma das apresentações dos resultados parciais do projeto ao Condepacc, em 13 de setembro de 2007, a equipe foi surpreendida com a seguinte notícia veiculada no Jornal Correio Popular:

\begin{abstract}
A Coordenadoria Setorial do Patrimônio Cultural (CSPC) apresentará hoje o resultado do Inventário da Região Central de Campinas que vem sendo realizado desde 2005 e que catalogou 6,7 mil imóveis construídos entre 1892 a 1945, dos quais pelo menos $40 \%$ poderão ser tombados pelo Conselho de Defesa do Patrimônio Artístico e Cultural de Campinas (Condepacc) (COSTA, 2007).
\end{abstract}

Afora as incorreções de ordem mais geral - do nome do Conselho ao recorte temporal -, a mais preocupante refere-se à suposta catalogação de 6,7 mil imóveis e à possibilidade de tombamento de pelo menos $40 \%$ desses. Como vimos, o número apresentado pelo jornal aproxima-se, na verdade, da ordem de grandeza dos requerimentos consultados no acervo do Arquivo Municipal de Campinas. Desses, evidentemente, uma enormidade se refere a imóveis já perdidos ao longo dos anos, e outros tantos se referem a um mesmo imóvel, já que foram registradas todas as intervenções por que passaram, desde o momento de sua construção. Ademais, a leviana informação de que ao menos $\underline{2680}$ edificações seriam tombadas provocou uma desenfreada procura pela CSPC para apresentação de solicitações de demolições, o que, em virtude da informalidade do inventário, não pudemos evitar.

Mas vale dizer, por fim, a despeito das dificuldades e das incompreensões, que a equipe responsável pelo inventário permanece dando continuidade às rotinas e 
tarefas estabelecidas, no aguardo de que um dia as políticas públicas dele derivadas recebam aval para sua completa implementação. Até lá, outros inventários surgidos de desdobramentos do projeto inicial, com novos recortes - espaciais e agora também temáticos -, começam a tomar forma.

\section{Notas}

(1) Abriga atualmente o Museu da Cidade de Campinas.

(2) Apenas dois meses antes, em outubro de 1987, Antonio Augusto Arantes, então Secretário de Cultura de Campinas, diria em entrevista, desconhecer a razão de a Câmara estar segurando a apreciação favorável do projeto de criação do conselho. (PORTINARI, 1987b).

(3) Disponível em <http://www.campinas.sp.gov.br/bibjuri/condepac.htm>.

(4) A Lei Municipal №. 5885 de 17 de dezembro de 1987 definiu como atribuições da CPC: localizar, identificar e inventariar os bens culturais do município; instruir os processos de tombamento e os referentes às áreas envoltórias dos bens tombados; propor ao conselho normas para a regulamentação dessas áreas; analisar solicitações para intervenções (construções, reformas, restauros, etc.) em áreas tombadas ou envoltórias; e apresentar pareceres para apreciação do Condepacc.

(5) O que já havia ocorrido cinqüenta anos antes, nos primeiros anos do Serviço do Patrimônio Histórico e Artístico Nacional (SPHAN), atual Instituto do Patrimônio Histórico e Artístico Nacional (IPHAN), na chamada fase heróica. Durante esse período, o principal instrumento de legitimação das escolhas realizadas era a autoridade dos técnicos, sendo desnecessário formular justificativas mais elaboradas. Sobre o assunto, cf. FONSECA, 2005, p. 81-130.

(6) A idéia de conjunto seria introduzida no Condepacc apenas com a abertura de estudo de tombamento do Complexo Ferroviário da Fepasa. Ainda assim, a noção de conjunto adotada é bastante questionável, visto que foram selecionados dentre os edifícios componentes do complexo ferroviário, aqueles passíveis de tombamento, prevalecendo puramente uma apreciação de caráter estético. Sobre o assunto, ver FRANCISCO, 2007.

(7) Os seis primeiros estudos abertos pelo Condepacc foram: Processo de Tombamento $\mathrm{n}^{\circ}$ 001/88 - Solar do Barão de Ataliba Nogueira; Processo de Tombamento $n^{\circ}$ 002/88 - Solar do Visconde de Indaituba; Processo de Tombamento $n^{\circ}$ 003/88 - Solar do Barão de Itapura; Processo de Tombamento $n^{\circ}$ 004/88 - Solar do Barão de Itatiba (Palácio dos Azulejos); Processo de Tombamento n005/88 - Catedral Metropolitana de Campinas e; Processo de Tombamento $n^{\circ}$ 006/88 - Capela de Nossa Senhora da Boa Morte.

(8) À frente trataremos com mais detalhes do recorte especial adotado para implementação do inventário.

(9) Dados sobre a metodologia de trabalho e os resultados obtidos pelo órgão federal de preservação podem ser 
conferidos em www.iphan.gov.br. Sobre o assunto conferir também MINC/IPHAN, 2005.

(10) Como vimos anteriormente, não são raras as vezes em que os órgãos de preservação, especialmente os conselhos estaduais e municipais de defesa do patrimônio, direcionam suas ações para respostas a determinadas demandas, sem condições de se antecipar e formular políticas de preservação para seus estados e municípios.

(11) Desde as primeiras movimentações para a realização de um inventário para Campinas, diversas pessoas, em vários momentos, ofereceram suas contribuições ao projeto. Desde que a autora assumiu a coordenação das rotinas de trabalho do inventário, em meados de 2005, acompanhando as atividades desenvolvidas por profissionais liberais contratados, estagiários e colegas da própria CSPC, destacamos a contribuição de: André Bertoni, Augusto Ottoni, Carolina Gutman, Denise Geribello, Fabíola Rodrigues, Izabele Szawka, Joana Canedo, Maria do Carmo Azevedo, Marina Cabrera, Nádia Zakia, Quincas Penteado, Sophia Caponi, Soraya Zanforlin, Thaís de Mendonça, Walquíria Gusson e, ainda, Paula Marques Braga, a quem agradecemos especialmente a valiosa colaboração e a permanência na equipe durante todo o desenvolvimento do projeto, mesmo nas fases de grandes dificuldades.

(12) O levantamento da planta cadastral do perímetro urbano do município de Campinas foi realizado pelo engenheiro Jorge Macedo Vieira, cujos serviços foram contratados pelo prefeito Orosimbo Maia. Viera foi responsável também, a partir desse levantamento cadastral, pelo reemplacamento da cidade, adotando o sistema de numeração por metro linear. Sobre essa base de dados Prestes Maia desenvolveu estudos para seus projetos de urbanismo que propiciaram, de um lado, a expansão dessa mancha urbana e, de outro, a completa remodelação do centro da cidade, com o alargamento de ruas e a conseqüente demolição de inúmeros imóveis.

(13) Vale ressaltar, no entanto, que os registros relativos a pedidos de autorização para construção, reformas, demolições, etc. encontrados no acervo histórico do Arquivo Municipal de Campinas se remetem a um período posterior, tendo início apenas em 1892.

(14) Há por exemplo, uma rica documentação primária nos registros constantes dos chamados livros de engenheiros, componentes do acervo do Arquivo Municipal de Campinas, que trazem informações sobre imóveis e construtores da cidade. A prática de registro nesses livros teve início apenas em 1930, mas esse corpus assim como outras bases documentais - foi incorporado ao material estudado. Do mesmo modo, os protocolados relativos a edificações, registrados em épocas posteriores, deverão ser contemplados em fases futuras do projeto, contribuindo significativamente para a identificação das diferentes configurações que um determinado imóvel tenha vindo a assumir.

(15) O sistema em desenvolvimento pela IMA, também prevê a futura alimentação com os dados dos trabalhos de campo.

(16) O sítio do patrimônio cultural do município de Campinas, disponível em <www.campinas.sp.gov.br/cultura/patrimonio> foi inaugurado em dezembro de 2007, como parte das comemorações pelos vinte anos do Condepacc. Além da futura divulgação dos resultados do Inventário, a página conta com a iniciativa inédita de disponibilizar na íntegra a visualização e o download de todos os processos de tombamento do órgão. 
(17) Uma vez que o inventário e os usos do patrimônio urbano não constituem um problema singular do município de Campinas, o banco de dados final a ser produzido deverá utilizar como parâmetros experiências bem sucedidas realizadas por outros órgãos de preservação, como aquelas do Instituto do Patrimônio Histórico e Artístico Nacional (IPHAN), do Instituto do Patrimônio Artístico e Cultural da Bahia (IPAC/BA), e do Instituto Estadual do Patrimônio Histórico e Artístico de Minas Gerais (IEPHA/MG).

(18) Esta resolução de tombamento, com a especificação da área envoltória, assim como as outras resoluções, leis e decretos relativos ao patrimônio cultural podem ser consultadas no sítio da Biblioteca Jurídica Municipal, disponível em <www.campinas.sp.gov.br/bibjuri/condepac2.htm>.

\section{Referências Bibliográficas}

CANCLINI, Nestor García. O patrimônio cultural e a construção imaginária do nacional. Revista do Patrimônio Histórico e Artístico Nacional, Brasília, DF: Iphan/Pró-memória, n. 23, p. 95-115, 1994.

CARDILLO, Denise. Condepacc: uma realidade inédita preservando Campinas antiga. Correio Popular, Campinas, 24 abr. 1988. [Acervo do Centro de Memória da Unicamp (CMU) - CMUHE009473].

CHUVA, Márcia (Org.). A Invenção do Patrimônio: continuidade e ruptura na constituição de uma política oficial de preservação no Brasil. Rio de Janeiro: IPHAN, 1995.

CONDEPACC vai avaliar imóveis para tombamento. Ver e Ouvir, Campinas, n. 27, p. 4-5, nov. 2007.

COSTA, Maria Teresa. Inventário vai nortear tombamento. Correio Popular, Campinas, 13 set. 2007.

CUNHA, Maria Clementina Pereira (Org.). O direito à memória: patrimônio histórico e cidadania. São Paulo: Departamento do Patrimônio Histórico, 1992.

CURY, Isabelle (Org.). Cartas Patrimoniais. Rio de Janeiro: Iphan, 2000.

FONSECA, Maria Cecília Londres. O patrimônio em processo: trajetória da política federal de preservação no Brasil. Rio de Janeiro: Editora UFRJ; MinC/Iphan, 2005.

FRANCISCO, Rita de Cássia. As oficinas da Companhia Mogiana de Estradas de Ferro: arquitetura de um complexo produtivo. Dissertação (Mestrado)-Faculdade de Arquitetura e Urbanismo da Universidade de São Paulo (FAUUSP), São Paulo, 2007.

FRANCISCO, Rita de Cássia et al. Patrimônio Cultural: entenda e preserve. Campinas: Secretaria Municipal de Cultura, 2005.

INVENTÁRIO de Proteção do Acervo Cultural de Minas Gerais (IPAC/MG). Instituto Estadual do Patrimônio Histórico e Artístico de Minas Gerais (IEPHA/MG). 2005.

JOKILEHTO, Jukka; FEILDEN, Bernard M. Manual para el manejo de los sitios del patrimonio mundial cultural. Bogotá: Instituto Colombiano de Cultura (Colcultura)/Subdirección de Patrimonio, 1995. 
LAPA, José Roberto do Amaral. A cidade: os cantos e os antros: Campinas 1850-1900. São Paulo: Edusp, 1996.

MILET, Vera. Base de informação para as tarefas da gestão. In: ZANCHETI, Sílvio Mendes (Org.). Gestão do patrimônio cultural integrado. Recife: Editora Universitária da UFPE, 2002. p. 125-132.

MINC/IPHAN. Inventário Nacional de Bens Imóveis - Sítios Urbanos Tombados 2001: produção técnica. Brasília, DF: Instituto do Patrimônio Histórico e Artístico Nacional.

Plano de preservação sítio histórico urbano. Termo geral de referência: produção técnica. ed. rev e aum.. Brasília, DF: Instituto do Patrimônio Histórico e Artístico Nacional, 2005. Disponível em: <http://portal.iphan.gov.br/portal/baixaFcdAnexo.do;jsessionid=52F259CE1F6AD627BE066CCDD5F61E4D?id=6 27>. Acesso em: 15/03/2006.

PORTINARI, Maria Helena. A luta em busca do equilíbrio entre o antigo e o novo. Jornal de Domingo, Campinas, 25 out. 1987. [Acervo do Centro de Memória da Unicamp (CMU) - CMUHE 007490].

O esclarecimento do secretário de Cultura. Jornal de Domingo, Campinas, 25 out. 1987. [Acervo do Centro de Memória da Unicamp (CMU) - CMUHE 007491].

PRESERVAÇÃO da Lidgerwood não é uma derrota, diz o prefeito. Correio Popular, Campinas, 12 jun. 1987. [Acervo do Centro de Memória da Unicamp (CMU) - CMUTO009200].

RUBINO, Silvana Barbosa. Inventário como ferramenta de preservação: produção técnica, 2005. Projeto de pesquisa apresentado ao Programa de Políticas Públicas da Fapesp. Campinas, Departamento de História da Universidade Estadual de Campinas (Unicamp), Campinas, 2005.

SINAL verde para o crescimento. Ver e Ouvir, Campinas, n. 27, nov. 2007. Contracapa.

UM DEBATE sobre preservar ou destruir: o crescimento de Campinas e a preservação do patrimônio foram objetos de debate promovido pela Fundação Pedroso Horta. Diário do Povo, Campinas, 18 jan. 1986. [Acervo do Centro de Memória da Unicamp (CMU) - CMUHE009479].

ZANCHETI, Sílvio Mendes (Org.). Conservation and urban sustainable development: a theoretical framework. Recife: Editora Universitária da UFPE, 1999.

* Arquiteta e Urbanista pela FAUUSP, especialista em Gestão do Patrimônio Cultural pelo CECI/UFPE, mestre em Arquitetura e Urbanismo pela FAUUSP. Agente cultural da Coordenadoria Setorial do Patrimônio Cultural da Prefeitura Municipal de Campinas.

e-mail: rcfrancisco@ig.com.br

Trabalho realizado com o apoio do Programa de Políticas Públicas da Fundação de Amparo à Pesquisa do Estado de São Paulo (Fapesp) 